\title{
Profile and scientific output analysis of physical therapy researchers with research productivity fellowship from the Brazilian National Council for Scientific and Technological Development
}

\author{
Giovani Sturmer ${ }^{1,2}$, Carolina C. M. Viero², Matheus N. Silveira², \\ Janice L. Lukrafka ${ }^{2}$, Rodrigo D. M. Plentz ${ }^{2}$
}

\begin{abstract}
Objective: To describe the profile and the scientific output of physical therapists researchers holding a research productivity fellowship (PQ) from the Brazilian National Council of Scientific and Technological Development (Conselho Nacional de Desenvolvimento Científico e Tecnológico-CNPq). Method: This is a cross-sectional study, which has evaluated the Lattes Curriculum of all PQ physiotherapy researchers registered at CNPq holding a research productivity fellowship in the period of 2010. The variables analyzed were: gender, geographic and institutional distribution, duration since doctorate defense, research productivity fellowship level, scientific output until 2010 and the H index in Scopus® and ISI databases. Results: A total of $55 \mathrm{PQ}$ from the CNPq were identified in the area of knowledge of Physical Therapy and Occupational Therapy, being $81.8 \%$ from the Southeast region of Brazil. They were predominantly female (61.8\%), with research productivity fellowship level PQ2 (74.5\%), and with average time since doctorate defense of $10.1( \pm 4.1)$ years. A total of 2.381 articles were published, with average of $42.5( \pm 18.9)$ articles/researcher. The average of articles published after doctorate defense was $39.40( \pm 18.9)$ articles/researchers with a mean output of $4.2( \pm 2.0)$ articles/year. We found 304 articles indexed in the Scopus ${ }^{\circledast}$ database with 2.463 citations, and 222 articles indexed in the Web of Science with 1.805 citations. The articles were published in 481 journals, being 244 (50.7\%) of them listed on JCR-web. The researchers presented a median 5 of the H index in the Scopus ${ }^{\circledR}$ database, and a median 3 in ISI. Conclusion: The scientific output of the researchers with research productivity fellowship in the field of physical therapy stands out in their indicators, since the figures are very promising for a relatively young area and as it can be observed by the amount of published articles and citations obtained by the national and international research community.
\end{abstract}

Keywords: scientific output indicators; bibliometric indicators; researcher performance evaluation systems.

HOW TO CITE THIS ARTICLE

Sturmer G, Viero CCM, Silveira MN, Lukrafka JL, Plentz RDM. Profile and scientific output analysis of physical therapy researchers with research productivity fellowship from the Brazilian National Council for Scientific and Technological Development. Braz J Phys Ther. 2013 Jan-Feb; 17(1):41-48. http://dx.doi.org/10.1590/S1413-35552012005000068

\section{- Introduction}

It has been observed a significant increase in the training of new researchers and also in the scientific output, not only in Brazil but also worldwide. This increase is allied to the development of science, technology and population welfare. In this context, several areas of knowledge and professions have developed new skills and practices based upon scientific evidence ${ }^{1,2}$.

Physical Therapy is an example of a profession that is in a fast professional development and it is essential that their members produce scientific knowledge for its consolidation ${ }^{3}$. It is well known that from this scientific output it is possible to extend and enhance the available knowledge, contributing to the development of guidelines for a more effective professional practice ${ }^{4}$. In addition, it is essential that clinical practice must be based on scientific evidence, especially when dealing with health conditions, and it is possible through the integration of knowledge produced by researchers from the field ${ }^{5,6}$.

Today, the scientific evidence produced by researchers in a particular field is published in high quality national and international journals that are, in general, indexed in respectable bibliographic databases ${ }^{7}$. On the other hand, the need of a scientific community to have indicators that can assist in setting guidelines for the allocation of resources and investments, program development and evaluation of activities related to scientific and technological

\footnotetext{
${ }^{1}$ Department of Health Sciences, Universidade de Cruz Alta (UNICRUZ), Cruz Alta, RS, Brazil

${ }^{2}$ Physical Therapy Department, Universidade Federal de Ciências da Saúde de Porto Alegre (UFCSPA), Porto Alegre, RS, Brazil

Received: 03/23/2012 Revised: 06/19/2012 Accepted: 09/18/2012
} 
development in the country is making essential the production of quantitative indicators in science, technology and innovation ${ }^{8}$.

Physical Therapy is a new profession that was regulated in Brazil 43 years ago. Physical Therapy has excelled in training new professionals in the health care field, consequently, it becomes crucial to establish quantitative and qualitative indicators relating to the production of scientific knowledge in this area. Therefore, it is important to identify the profile of the researchers working in this area of knowledge, as well as the related scientific output ${ }^{7}$. A study published in 2009, aimed to identify the profile of Brazilian physical therapist researchers found a remarkable increase $(900 \%)$ in the number of physical therapists with a doctorate degree in Brazil in the last decade, which indicates the search for higher educational training of these professionals. Connected to this aspect is a larger development in research, which generates the enhancement of the profession and consequently improve the labor market and in the services delivered to the population ${ }^{7}$.

Additionally, in the last years, few studies have analyzed the profile and scientific output of researchers with research productivity fellowships (PQ) from the Brazilian National Council of Scientific and Technological Development Conselho Nacional de Desenvolvimento Científico e Tecnológico $(\mathrm{CNPq})$ in many areas of knowledge ${ }^{9,10}$. This research productivity fellowship was created in the 70s as an approach to encourage researchers holding a doctoral degree and with outstanding scientific output in their areas, in order to enhance their work compared to their peers ${ }^{11}$.

Thus, a profile and scientific output analysis of the current physical therapist researchers holding a research productivity fellowship will allow the construction of quantitative and qualitative indicators in this area of knowledge and professional practice. From the CNPq Lattes Platform it is possible to obtain information about the Brazilian researchers curriculum. The CNPq Lattes Platform provides an online curriculum, which is filled in by the researchers themselves, becoming a system of easy access with rich information about the scientific output of the academic community. Therefore, the aim of this study was to describe the profile and scientific output of physical therapist researchers holding a research productivity fellowship from the CNPq.

\section{Method}

A descriptive cross-sectional study was conducted, which included a total of 55 physical therapist researchers holding a PQ fellowship in the Physical Therapy area in the period of 2010, according to information provided by $\mathrm{CNPq}^{12}$. Those researchers without a Physical Therapy degree, with suspended PQ fellowship and physical therapists with PQ fellowship in other areas of knowledge were excluded.

In order to obtain a profile of physical therapist researchers and of their scientific output, two independent researchers analyzed the curricula available in the CNPq Lattes Platform ${ }^{13}$, and a extraction form was created with following the variables: gender; geographic and institutional distribution; duration since doctorate defense; research productivity fellowship level; scientific output (scientific articles published); number of completed supervisions; list of journals and $\mathrm{H}$-index in the Scopus database (http://www.scopus.com/ home.url) ${ }^{14}$ and Web of Science Thomson - Institute for Scientific Information - ISI (http://apps. isiknowledge.com $/)^{15}$, through the Coordination of Improvement of Higher Education Personnel (CAPES) website (www.capes.gov.br). The scientific articles published by PQ researchers were examined, through the CAPES website, using the authors scientific names provided by the Lattes Curriculum, considering the author name variations indicated in the Lattes curriculum and also in the published articles. The H-Index was created in 2005 by the physicist Jorge E. Hirsch from the University of California ${ }^{16}$. This index is a proposal to quantify the productivity and the impact of researchers, based on their most cited articles, being even incorporated into the CNPq Lattes Platform ${ }^{17}$. In other words, the $\mathrm{H}$-index is the number of articles published by the researcher, which obtain citation number greater than or equal to the number of articles. For example, a researcher with $\mathrm{H}$-index $=15$ has 15 published articles that received at least 15 citations each ${ }^{16}$.

With regards to the publications list presented in the Lattes Curriculum of each PQ researcher, the total number of published articles related to the entire scientific career and also the number of articles published after the doctorate degree were evaluated. The publications were also adjusted by the time since doctorate defense. Another extracted form was composed of articles published by all researchers until 2010, excluding the duplicate articles. This data was collected to evaluate in which scientific journals the articles were published, stratifying in indexed and not indexed journals in the Journal Citation Reports (JCR). All data collection was performed in July 2011. 
All collected data mentioned above was included on a electronic spreadsheet, and descriptive statistical analysis was performed using SPSS (version 18.0). The results were presented as frequency and percentage, and the continuous data were described using mean and standard deviation for normally distributed variables and medians and interquartile ranges (between the 25th and 75th percentiles) for asymmetric data.

\section{- Results}

Fifty-five physical therapists researchers holding a research productivity fellowship in 2010 from the $\mathrm{CNPq}$ were identified. The distribution by gender and research fellowship level are presented in Table 1, showing a predominance of female researchers (61.8\%) and research fellowship level 2 - PQ-2 $(74.5 \%)$.

\section{Time since doctorate defense}

In the analysis of time since doctorate defense, the observed mean time was $10.1(\mathrm{SD} \pm 4.1)$ years, with a similar distribution percentage among doctors with up to 10 years $(50.9 \%)$ and with doctors with more than 10 years since doctorate defense. The most prevalent range was between 11 and 15 years (38.2\%), followed by 6 to 10 years $(30.9 \%), \leq 5$ years (20\%) and lastly the researchers with more than 15 years since doctorate defense (10.9\%).

\section{Geographic and institutional distribution}

The geographical distribution showed that the Southeast region of Brazil accounts for $81.8 \%$ of researchers with PQ fellowship (Table 2). In the analysis of the institutions where the researchers are located, it was observed that they were distributed in 16 universities around the country. However, four of them were responsible for $58.1 \%$ of researchers with PQ fellowship: UFSCar (20\%); UFMG (16.3\%); USP-São Paulo (10.9\%) and UNINOVE (10.9\%).

\section{Supervision completions}

The PQ researchers supervised a total of 120 doctoral theses, 659 master theses and 971 scientific initiations during their total academic career. The average supervision completion for doctoral degree was 2.18 ( $\mathrm{SD} \pm 3.6$ ), for master degree was $11.9(\mathrm{SD} \pm 7.3)$ and for scientific initiation was $17.9(\mathrm{SD} \pm 13.1)$ students per researcher, however these distributions were skewed. The description of the medians and interquartile ranges are described in Table 3 and demonstrate the wide variation in the number of supervision completions.

\section{Publications/journals}

The total scientific output along the academic career of all included researchers was 2,341 articles published in scientific journals, with a mean of 42.5 $( \pm 18.9)$ articles published per researcher. The mean of articles published in scientific journal since the doctorate defense was $39.4( \pm 18.9)$. The average number of articles published, corrected by time (in years) since doctorate defense, was $4.2(\mathrm{SD} \pm 2.0)$ articles/year.

A total of 1,067 articles indexed in the Journal Citation Reports on the $\mathrm{Web}^{\circledR}$ (JCR-Web) database were observed in the researchers curriculum, corresponding to $52.5 \%$ of the articles published. A total of 304 articles were indexed in the Scopus database, in which 2,463 citations have been identified; and 222 articles were indexed in the Web of Science database, with 1,805 citations.

Considering the total number of articles published, it was observed the use of 481 different journals, being 244 indexed and 237 non-indexed in JCR-Web.

Table 1. Distribution of researchers by gender and research productivity fellowship level.

\begin{tabular}{ccccccc}
\hline PQ fellowship levels & \multicolumn{2}{c}{ Male } & \multicolumn{3}{c}{ Female } & \multicolumn{2}{c}{ Total } \\
PQ-1 A & N & \% & N & $\%$ & N & $\%$ \\
PQ-1 B & 0 & 0.0 & 1 & 1.8 & 1 & 1.8 \\
PQ-1 D & 2 & 3.6 & 4 & 7.2 & 6 & 10.9 \\
PQ-2 & 3 & 5.4 & 3 & 5.4 & 6 & 10.9 \\
PQ-2 F & 16 & 29.1 & 25 & 45.4 & 41 & 74.5 \\
Total & 0 & 0.0 & 1 & 1.8 & 1 & 1.8 \\
\hline
\end{tabular}

$\mathrm{PQ}=$ research productivity fellowship. 
Table 2. Distribution of PQ fellowship by researchers' region and institution.

Variable $\quad$ N (55) $\quad \%$

\section{Brazil Region}

$\begin{array}{lcr}\text { Southeast } & 45 & 81.8 \\ \text { South } & 4 & 7.2 \\ \text { Northeast } & 6 & 10.9\end{array}$

Institution

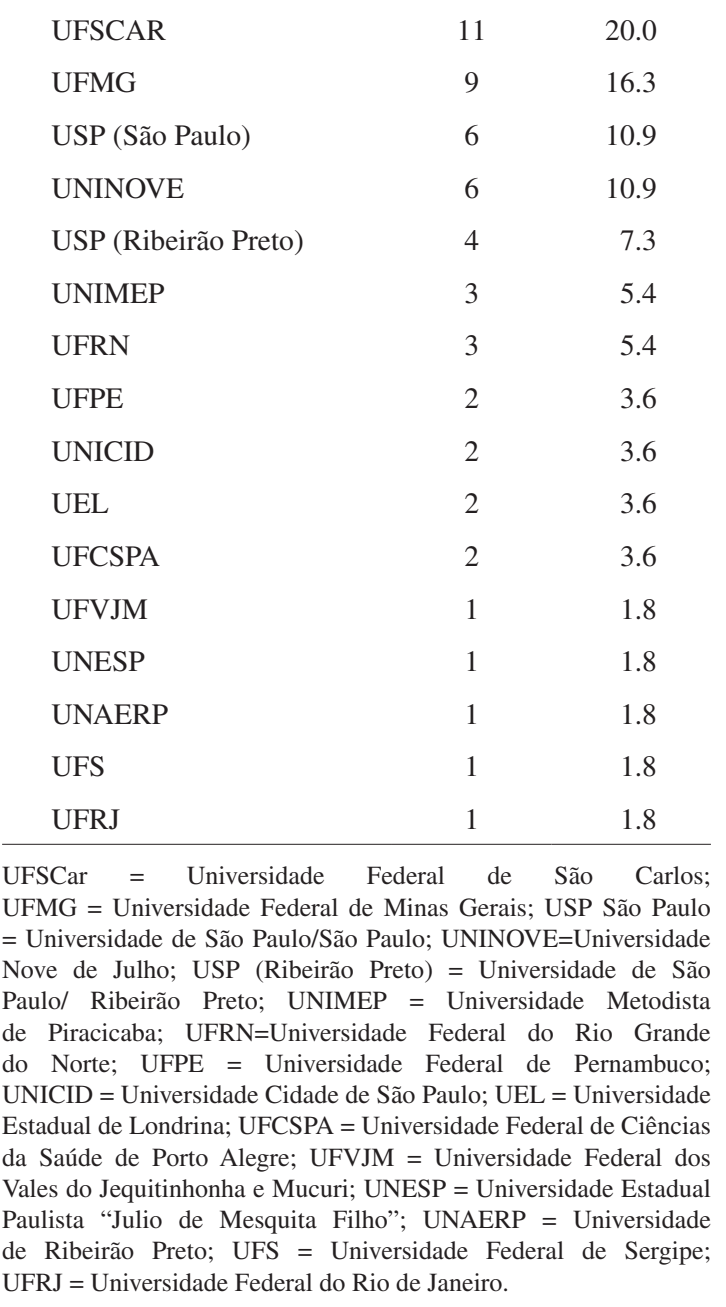

The impact factor of the journals ranged between a minimum of 0.03 and maximum of 14.3 , with a median of 2.05 (IQ = 1.429 to 2.804 ). The impact factor obtained from the 10 journals with more publications that are indexed in JCR-Web reached a mean of $1.7( \pm 0.82)$. In this database, 8,073 journals are indexed, being the impact factor ranging from 0 to 94.3 in the year of 2010 .

With regards to the scientific journals, Table 4 presents a list of the 10 indexed and the 10 not indexed scientific journals in the JCR-Web most used by PQ
Table 3. Doctorate, Master's degrees, scientific initiation supervision completion and H-Index of the PQ physical therapy researchers.

\begin{tabular}{|c|c|c|c|c|}
\hline Variable & \multicolumn{2}{|c|}{ Median IQ (25-75) } & \multirow[t]{2}{*}{ Min $^{a}$} & \multirow[t]{2}{*}{$\operatorname{Max}^{\mathbf{b}}$} \\
\hline Supervision completion & & & & \\
\hline Doctorate degree & 1 & $0-2.5$ & 0 & 20 \\
\hline Master degree & 12 & $6-15.5$ & 2 & 36 \\
\hline Scientific Initiation & 15 & $9-21.7$ & 0 & 58 \\
\hline \multicolumn{5}{|l|}{ H-index } \\
\hline Scopus database & 5.3 & $3-7$ & 1 & 12 \\
\hline Web of Science database & 3 & $2-6$ & 0 & 11 \\
\hline
\end{tabular}

${ }^{\mathrm{a}}$ minimum; ${ }^{\mathrm{b}}$ maximum.

physical therapist researchers for their publications. It was observed that the number of articles published in the 10 most used journals indexed in JCR-Web is almost half of the total number of the publications in this group of journals. Similarly, the same pattern occurs in the 10 journals that are not indexed in JCR-Web, which demonstrate a preference for some journals by the researchers for publishing their studies.

In 2010, 44 journals in the Rehabilitation area were indexed in the ISI database, with an impact factor ranging from 0.000 to 3.772 $($ median $=1.29-\mathrm{IQ}=0.639$ to 1.989$)$. In the Sport Science area, 80 journals were identified with an impact factor ranging between 0.07 and 5.07 ( median $=1.204-\mathrm{IQ}=0.669$ to 2.224 ). Regarding the Brazilian journals, there were 89 indexed in ISI in various areas of knowledge, in which $33(37 \%)$ were from health care area, being only one journal (1.12\%) specific to the physical therapy area.

\section{H-Index}

Physical Therapy researchers received a total of 2,463 citations in the Scopus database and 1,805 citations in the Web of Science database during their academic carees.

The median H-index observed in the Scopus database in 2010 was 5.3 (IQ = 3 to 7) and a median of 3 (IQ $=2$ to 6 ) when evaluated in the Web of Science database (Table 3 ).

\section{Discussion}

The results of this study demonstrated important indicators regarding the profile and the scientific output of physical therapist researchers with research productivity fellowship from $\mathrm{CNPq}$ in the Physical 
Table 4. List of the 10 most commonly used indexed journals, and the 10 most commonly used not indexed journals in JCR-Web, by the physical therapists researchers, by publication.

\begin{tabular}{|c|c|c|c|c|}
\hline \multirow{13}{*}{ 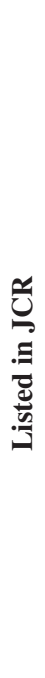 } & Journals & JCR & Publications $^{\mathrm{a}}$ & $\%^{b}$ \\
\hline & Revista Brasileira de Fisioterapia & 0.368 & 301 & 14.8 \\
\hline & Brazilian Journal of Medical and Biological Research & 1.150 & 57 & 2.8 \\
\hline & Acta Cirúrgica Brasileira & 0.500 & 26 & 1.3 \\
\hline & Photomedicine\& Laser Surgery & 1.633 & 23 & 1.1 \\
\hline & Journal of Electromyography and Kinesiology & 2.372 & 22 & 1.1 \\
\hline & Clinics & 1.422 & 19 & 0.9 \\
\hline & Lasers In Medical Science & 2.311 & 15 & 0.7 \\
\hline & Respiratory Medicine & 2.525 & 14 & 0.7 \\
\hline & Toxicon & 2.451 & 14 & 0.7 \\
\hline & Gait \& Posture & 2.313 & 12 & 0.6 \\
\hline & Total number of articles in the 10 most used journals with JCR & & 503 & 24.8 \\
\hline & Total of indexed articles & & 1067 & 52.5 \\
\hline \multirow{13}{*}{ 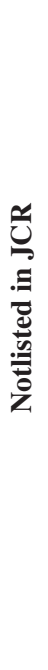 } & Fisioterapia em Movimento & & 91 & 4.5 \\
\hline & Fisioterapia Brasil & & 68 & 3.3 \\
\hline & Terapia Manual & & 62 & 3.1 \\
\hline & Revista Fisioterapia e Pesquisa & & 45 & 2.2 \\
\hline & Revista de Fisioterapia da Universidade de São Paulo & & 43 & 2.1 \\
\hline & Revista Brasileira de Medicina do Esporte & & 39 & 1.9 \\
\hline & Fisioterapia e Pesquisa & & 30 & 1.5 \\
\hline & ConScientiae Saúde & & 28 & 1.4 \\
\hline & Acta Fisiátrica & & 23 & 1.1 \\
\hline & Electromyography and Clinical Neurophysiology & & 23 & 1.1 \\
\hline & Total number of articles in the 10 most used journals without JCR & & 452 & 22.3 \\
\hline & Total of not indexed articles & & 964 & 47.5 \\
\hline & Total of published articles & & 2031 & 100 \\
\hline
\end{tabular}

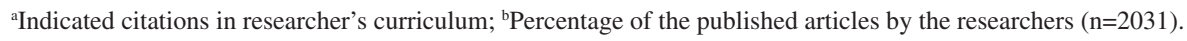

Therapy area. It is important to highlight that the research productive fellowship was created with the aim to encourage researchers holding a doctorate degree and also with outstanding scientific output in their field for valuing their work comparing to their peers ${ }^{11}$; being this fellowship an important mechanism for valuing the work of the Brazilian researches supported by the Ministry of Science and Technology of Brazil.

The data obtained from the CNPq Lattes Platform for this research denote the reliability of the information presented by the researchers in their online curricula. This platform is used nationally and also internationally, as a form of record the scientific output and academic career of researchers. The platform works as an opened record with an abundance of information and details, besides having mechanisms that enable greater reliability and completeness of the information declared ${ }^{18}$.

Regarding the profile of the researchers, we found that most of the researchers with PQ fellowship were female, and the research productivity fellowship level 2 (PQ-2) was the most frequent. We could also observe that the PQ fellowships were distributed to researchers with varied time of since doctorate defense and were more concentrated in the Southeast region of the Brazil.

The distribution of Physical Therapy research productivity fellowship by gender presented a considerable difference when compared to other areas, such as Medicine ${ }^{19}$, Cardiology ${ }^{11}$, and Nephrology/Urology ${ }^{20}$ and Chemistry ${ }^{3}$, which 
most researchers productivity fellows were male. In addition, these studies ${ }^{3,11,19,20}$ presented higher percentage of researchers with research productivity fellowship level 2 (PQ-2), which is similar to the results found in our study. However, researchers holding a PQ-2 were not related to time since doctorate defense. Although $51 \%$ of researchers have under 10 years of doctorate defense, a larger proportion of researchers with greater time since doctorate defense also has the same level of research productivity fellowship. This pattern of distribution may be more related to the researcher scientific output and also due to the smaller availability of research productivity fellowship in higher levels (level 1). The higher prevalence of female researchers with PQ fellowship may be related to the historical process of the physical therapy profession in Brazil ${ }^{21}$ and also due to the greater number of women working in research and teaching in Physical Therapy courses.

The concentration of PQ fellows in the Southeast region of Brazil has a direct relationship with the fact that the first physical therapy courses were originated in the states of this region (Rio de Janeiro, São Paulo and Minas Gerais, Brazil), as well as the first postgraduate research courses, being the only two existing Doctoral programs in physical therapy located in the Southeast of Brazil in 2010. Among the 10 existing Master courses degree and the two Doctoral courses degree in physical therapy, recommended by CAPES, half of them were located in the state of São Paulo, and only three Master courses were located outside the Southeast region ${ }^{22}$. It is known that post-graduation programs attract researchers with doctorate degree, and that most of the scientific output is linked to the research studies developed inside these programs $^{23}$. Thus, it is possible to explain the higher concentration of PQ fellowship for researchers in this region of Brazil.

This regional concentration of researchers with PQ fellowship and scientific output is also observed in many areas of knowledge, such as Chemistry ${ }^{3}$ and Medicine $^{19}$. It is important to highlight that the North and Midwest regions of Brazil present no physical therapist researcher with PQ fellowship, which reinforces the heterogeneous spatial distribution in the country. Similarly, there are no post-graduate research programs in the Physical Therapy in these regions. This finding should subsidize specific government actions to address such regional differences.

Researchers with PQ fellowship have an important role in the training of qualified human resources, which can be observed by the number of supervisions at undergraduate (Scientific Initiation) and post-graduate levels (Masters and Doctorate). It was observed that the number of supervisions adjusted by the time since Doctorate defense per researcher were higher in Master level and lower number for Doctorate per year, when compared with other areas, such as Medicine ${ }^{19}$, Nephrology and Urology ${ }^{20}$. This result should be considered a reflection of the recent recognition of Physical Therapy as a regulated profession in Brazil and the recent development of research and post-graduation in this area of knowledge, a fact that can be seen by the lifetime of the first post-graduate research program in Physical Therapy, implanted by UFSCar only 15 years ago.

It is important to highlight that, in a universe of approximately 660 physical therapists holding a Doctorate degree, only $55(8.3 \%)$ are researchers with PQ fellowship from CNPq. This percentage decreases considerably $(0.03 \%)$ when consider more than 150.000 registered physical therapists in the Federal Council of Physical Therapy and Occupational Therapy (COFFITO) ${ }^{24}$ in Brazil, which demonstrates the need to expand the number of research productivity fellowship, as well as increased the amount of funding for Physical Therapy area. Although we recognize the effort that research funding agencies, in particular the $\mathrm{CNPq}$ and CAPES have done to support research and human resources training in Brazil ${ }^{25}$, enabling an increase of $85.7 \%$ in the number of research fellowship/ grants in the physical therapy area between 2007 and $2010^{26}$, it should be noted that the small number of PQ fellowships in the Physical Therapy area can cause negative consequences for scientific output, especially with the lack of this incentive for young and productive researchers.

A form to demonstrate the relevance of the scientific output is through the analysis of scientific output indicators and the impact of the research on the society. It can be measured by the number of publications and by the number of international citations for each publication, as well as the set of publications in a given area. In general, the scientific output in the Physical Therapy area and in others health-related areas have achieved important indicators, as it can be observed in SCImago database (Journal \& Country Rank) ${ }^{27}$, where in the Physical Therapy, Sports Therapy and Rehabilitation category, Brazil was ranked $6^{\text {th }}$ in the total number of articles published during the year 2010. When compared to the scientific output from other countries in the same category, it can be observed the growth and the importance of the Brazilian scientific output 
in Physical Therapy on the world scenario. It is unequivocally the participation of researchers holding a PQ fellowship in obtaining these indicators, as well as the participation of other researchers who have no PQ fellowship.

A relevant data that support the statement above is the average of articles published by PQ researchers, adjusted for time since Doctorate defense (4.2 articles/ year), which shows similar values compared to the scientific output of researchers from other healthrelated areas, such as Nephrology and Urology $(4 \text { articles/year })^{20}$, Cardiology (4.4 articles/year) ${ }^{11}$ and the large area of Medicine (4.1 articles/year) ${ }^{19}$. This level of productivity shows that researchers in the Physical Therapy area are involved and committed to the production of scientific knowledge and present indicators equivalent to $\mathrm{PQ}$ researchers in other areas of practice. Regarding the impact measured by the H-index of PQ researchers in the Physical Therapy area, it was observed a median of 5.3 in the Scopus database and 3.0 in Web of Science database. This values are lower compared to researchers from other health-related areas, such as Cardiology (Scopus - median $=11-\mathrm{IQ}=8.5$ to 16 ; Web of Science - median $=10-\mathrm{IQ}=8$ to 14.5$)^{11}$ and Nephrology and Urology (Scopus - median $=11$ - IQ = 7 to 17; Web of Science - median $=10-\mathrm{IQ}=7$ to 16$)^{20}$. These differences, in part, can be explained by the smaller number of journals in the Physical Therapy area indexed in international databases and also due to the short-time existence of the profession and the specific area of knowledge of Physical Therapy compared to older areas, such as Medicine. One possible way to increase these indicators of quality and relevance would be, in addition to the increase of number of PQ fellows in the area, the incentive for interaction between groups from different areas of knowledge, strengthening of research networks ${ }^{25}$, as well as the expansion of journals indexed in international databases. It is important to emphasize that due to the fast growth in the scientific production, it is possible that the values observed in the $\mathrm{H}$-index and in the other variables evaluated are not reflecting the current moment of the area production, which is in constant progression.

Is also important to note that the set of journals that published most of the articles from researchers with PQ fellowship in the Physical Therapy area can be an epistemological reference that deserves greater attention by the research funding agencies that evaluate and qualify the national and international journals and researchers from the area. In this context, we highlight that Brazilian Journal of Physical
Therapy is one of the most important vehicles for the dissemination of knowledge and scientific output in Physical Therapy in our country.

A limitation of our study is that the data collected may be misleading or incomplete, as it was collected by the informed data from the Lattes Curriculum of the researchers investigated. Despite the fact that the Lattes Curriculum is an important tool for information and national and international scientific visibility, its correct completion form depends on the researchers themselves, and therefore the problems identified are likely.

\section{Conclusion}

The profile and the scientific output of researchers holding a research productivity fellowship from CNPq in the Physical Therapy area stand out in their indicators, since the numbers are very promising for a relatively new professional area in the national and international scenario. However, there was a concentration of researchers in the Southeast region, coinciding with the concentration of post-graduate research programs, and a small amount of $\mathrm{PQ}$ fellows in relation to the number of professionals and doctors in the Physical Therapy area in Brazil

\section{References}

1. Zorzetto R, Razzouk D, Dubugras MTB, Gerolin J, Schor N, Guimarães JA, et al. The scientific production in health and biological sciences of the top 20 Brazilian Universities. Bras J Med Biol Res. 2006;39(12):1513-20. PMid:17160259. http://dx.doi.org/10.1590/S0100-879X2006005000040

2. Deheinzelin D, Caramelli B. Scientific production, postgraduate education and Revista da Associação Médica Brasileira. Rev Assoc Med Bras. 2007;53(6):471-2. http:// dx.doi.org/10.1590/S0104-42302007000600001

3. Santos NCF, Candido LFO, Kuppens CL. Produtividade em pesquisa do CNPq: análise do perfil dos pesquisadores da Química. Quím Nova. 2010;33(2):489-95. http://dx.doi. org/10.1590/S0100-40422010000200044

4. Richter RR, Schlomer SL, Krieger MM, Siler WL. Journal publication productivity in academic physical therapy programs in the United States and Puerto Rico from 1988 to 2002. Phys Ther. 2008;88(3):376-86. PMid:18096652.

5. Maher CG, Sherrington C, Elkins M, Herbert RD, Moseley AM. Challenges for evidence-based physical therapy: accessing and interpreting high-quality evidence on therapy. Phys Ther. 2004;84(7):644-54. PMid:15225083.

6. Harris SR. Letter to the editor. On "Journal publication productivity..." Richter et al. Phys Ther 2008;88(3):376-86. Phys Ther. 2008;88(6):791. http://dx.doi.org/10.2522/ ptj.2008.88.6.791 
7. Coury HJCG, Vilella I. Profile of the Brazilian physical therapy researcher. Rev Bras Fisioter. 2009;13(4):356-63. http://dx.doi.org/10.1590/S1413-35552009005000048

8. Mugnaini R, Packer AL, Meneghini R. Comparison of scientists of the Brazilian Academy of Sciences and of the National Academy of Sciences of the USA on the basis of the h-index. Braz J Med Biol Res. 2008;41(4):258-62. PMid:18392447.

9. Barata RB, Goldbaum M. Perfil dos pesquisadores com bolsa de produtividade em pesquisa do CNPq da área de saúde coletiva. Cad Saúde Pública. 2003;19(6):1863-76. http://dx.doi.org/10.1590/S0102-311X2003000600031

10. Santos SMC, Lima LS, Martelli DRB, Martelli-Júnior H. Perfil dos pesquisadores da Saúde Coletiva no Conselho Nacional de Desenvolvimento Científico e Tecnológico. Physis. 2009;19(3):761-75. http://dx.doi.org/10.1590/ S0103-73312009000300012

11. Oliveira EA, Ribeiro ALP, Quirino IG, Oliveira MCL, Martelli DR, Lima LS, et al. Profile and scientific production of CNPq researchers in cardiology. Arq Bras Cardiol. 2011;97(3):186-93. http://dx.doi.org/10.1590/ S0066-782X2011005000086

12. Conselho Nacional de Desenvolvimento Científico e Tecnológico - CNPq. Bolsas. [cited 2011]. Available from: http://www.cnpq.br/web/guest/bolsas2.

13. Conselho Nacional de Desenvolvimento Científico e Tecnológico - CNPq. Plataforma Lattes. [cited 2011 July]. Available from: http://lattes.cnpq.br.

14. Scopus. Search.2011 [cited 2011 July]. Available from: http://www.scopus.com/search.url.

15. Institute for Scientific Information - ISI. Web of Knowledge. Web of Science. [cited 2011 July]. Available from: http://apps.webofknowledge.com/ UA_GeneralSearch_input.do?product=UA\&search_ mode $=$ General S e a c c \& S ID=1EpfFB B @ Ni8fgj2E1om\&preferencesSaved=.

16. Hirsch JE. An index to quantify an individual's scientific research output. Proc Natl Acad Sci USA. 2005;102(46):16569-72. http://dx.doi.org/10.1073/ pnas.0507655102

17. -Kellner AW, Ponciano LC. H-index in the Brazilian Academy of Sciences: comments and concerns. An Acad Bras Cienc. 2008;80(4):771-81. PMid:19039498.

18. Conselho Nacional de Desenvolvimento Científico e Tecnológico - CNPq. Histórico. 2012. [cited 2012 May]. Available from: http://www.cnpq.br/web/guest/a-criacao.

19. Martelli-Junior H, Martelli DRB, Quirino IG, Oliveira MCLA, Lima LS, Oliveira EA. Pesquisadores do CNPq na área de medicina: comparação das áreas de atuação. Rev Assoc Med Bras. 2010;56(4):478-83. http://dx.doi. org/10.1590/S0104-42302010000400024

20. Oliveira EA, Pécoits-Filho R, Quirino IG, Oliveira MC, Martinelli DR, Lima LS, et al. Perfil e produção científica dos pesquisadores do CNPQ nas áreas de Nefrologia e Urologia. J Bras Nefrol. 2011;33(1):31-7. http://dx.doi. org/10.1590/S0101-28002011000100004

21. Machado MH, Wermelinger M, Tavares MFL, Moysés NMN, Teixeira M, Oliveira ES. Análise da força de trabalho do setor saúde no Brasil: focalizando a feminização. Rio de Janeiro: Fundação Oswaldo Cruz, Rede Observatório de Recursos Humanos em Saúde; 2006.

22. Geocapes. Sistema de dados georreferencial da Coordenação de Aperfeiçoamento de Pessoal de Nível Superior. [cited 2012 May]. Available from: http:// geocapes.capes.gov.br/geocapesds/\#app $=c 501 \&$ da7aselectedIndex $=0 \& 5317$ - selectedIndex $=1 \& 82 \mathrm{e} 1$ selectedIndex $=0$.

23. Coordenação de Aperfeiçoamento de Pessoal de Nível Superior - CAPES. 2006. [cited 2012 June]. Available from: http://www.capes.gov.br/servicos/ sala-de-imprensa/36-noticias/1423.

24. Conselho Federal de Fisioterapia e Terapia Ocupacional - COFFITO. [cited 2011 Oct]. Available from: http://www.coffito.org.br/faqs/faq.asp.

25. Sampaio RF, Salvini TF. Challenges for the advance of physical and occupational therapy research. Rev Bras Fisioter. 2011;15(5):v-vi. http://dx.doi.org/10.1590/ S1413-35552011000500001

26. Coury HJCG, Mancini MC. Three years of accomplishments at CNPq. Rev Bras Fisioter. 2010;14(4):v-vii. http://dx.doi. org/10.1590/S1413-35552010000400001

27. SCImago. SCImago Journal and Country Rank. 2011. [cited 2012 June]. Available from: http://www.scimagojr. com.

\section{Correspondence}

\section{Rodrigo Della Méa Plentz}

Universidade Federal de Ciências da Saúde de

Porto Alegre (UFCSPA)

Departamento de Fisioterapia

Rua Sarmento Leite, 245, Centro

CEP 90050-170, Porto Alegre, RS, Brasil

e-mail: roplentz@yahoo.com.br; rodrigop@ufcspa.edu.br 